\title{
Presymptomatic testing of those at $25 \%$ risk of autosomal dominant neurodegenerative disease- testing team beware
}

\author{
Martin B. Delatycki ${ }^{1}$
}

Received: 14 September 2018 / Accepted: 14 September 2018 / Published online: 5 October 2018

(c) European Society of Human Genetics 2018

Bonnard and colleagues report on their experience of testing individuals at $25 \%$ risk of having inherited the exon 1 HTT CAG trinucleotide repeat expansion that underlies Huntington disease [1]. Approximately $10 \%$ of all requests for Huntington disease presymptomatic testing to this team were from individuals at $25 \%$ risk (155 individuals). Sixty percent of these individuals were tested of whom 14 received a gene-positive result meaning they had the CAG expansion and thus their at-risk parent must also have had this. At least 4/14 (22\%) at-risk parents had an adverse reaction on being informed of their gene-positive status including one suicide. Bonnard and colleagues compare those who requested testing at $25 \%$ risk to those who requested testing at $50 \%$ risk. Unsurprisingly those at $25 \%$ risk were younger and less often had children than those at $50 \%$ risk. Those at $25 \%$ risk were more likely to withdraw from the testing procedure than those at 50\% risk [1].

Presymptomatic genetic testing is remarkable in that it is one of the few tests that a person can have that can reveal very important information about a third party who may not wish to have such information. Only around 13\% of individuals at $50 \%$ risk of inheriting the CAG trinucleotide repeat expansion in exon1 of $H T T$ choose to have this testing [2]. Where the child of a person at $50 \%$ risk wishes to have testing they are described as being at $25 \%$ risk. There has been much discussion in the literature about the approach to testing such individuals. The international guidelines for presymptomatic genetic testing of individuals at risk of Huntington disease state that "Extreme care should be exercised when testing would provide information about another person who has not requested the test. This will

Martin B. Delatycki

martin.delatycki@vcgs.org.au

1 Victorian Clinical Genetics Services, Murdoch Children's Research Institute, Flemington Road, Parkville 3052 Victoria, Australia arise when an individual(s) at $25 \%$ risk request(s) testing with full knowledge that his/her parent does not want to know his/her status. Every effort should be made by the counsellors and the individuals concerned to come to a satisfactory solution of this conflict" [3]. No advice is provided about what "satisfactory solution of this conflict" may be.

The high rate of negative impact on parents whose status is revealed by genetic testing in the study by Bonnard and colleagues [1] is something that requires attention when individuals request testing at $25 \%$ risk where their at-risk parent is alive and does not wish to learn their status. There appears to be a higher rate of negative impact when a parent's gene-positive status is revealed by testing of their child than when individuals at 50\% risk are tested and found to be gene positive. A very large study by Almqvist and colleagues identified that approximately $2 \%$ of individuals who received a gene-positive result had a so-called catastrophic reaction defined as suicide, attempted suicide or hospitalisation for psychiatric impact [4]. Bonnard and colleagues noted that their figures for adverse outcomes are minimum figures since they did not follow-up with the parents of gene-positive individuals tested at $25 \%$ risk in a systematic manner.

The lessons learnt from the study by Bonnard and colleagues [1] are that testing individuals at $25 \%$ risk of a neurodegenerative disorder for which no interventions are proven to delay onset or slow the progression can be associated with significant impact for those who have not requested testing; the 50\% at-risk parent. It reinforces that every effort must be made to involve the at-risk parent in the testing process. At least by involving the parent that person is given the choice of testing first, and, if they choose not to have testing, they can receive professional support rather than finding out the result from their child who themselves will be psychologically impacted by finding out that they have the mutation for the condition. At times those at $25 \%$ risk will request testing and will plan not to inform their at-risk parent that they are having testing and therefore 
plan not to inform their at-risk parent of their genetic status should a gene positive result ensue. The ethical issues that this raises and the approach to this have been discussed previously [5].

In light of the findings of Bonnard and colleagues [1], the next iteration of international guidelines for presymptomatic testing for Huntington disease should highlight this study to make very clear that testing individuals at $25 \%$ risk and informing the at-risk parent of their genetic status should a gene positive result ensue can have very significant impact for that parent including suicide. I suggest that the guideline in relation to this scenario is stronger in providing advice to those faced with this request than is the case for the current guideline. I recommend that the guideline states that adverse outcomes are common for parents of those tested at $25 \%$ risk and found to be gene positive who are subsequently informed of the result. In light of this, such testing should only take place after every effort is made to engage with the at-risk parent to give them the opportunity to have testing themselves and if they decline this, to have professional support available at the time they are informed of the result of their child's testing.

\section{Compliance with ethical standards}

Conflict of interest The author declares that he has no conflict of interest.

\section{References}

1. Bonnard A, Herson A, Gargiulo M, Durr A. Reverse presymptomatic testing for Huntington disease: double disclosure when $25 \%$ at-risk children reveal the genetic status to their parent. Eur J Hum Genet. https://doi.org/10.1038/s41431-018-0255-7.

2. Tassicker RJ, Teltscher B, Trembath MK, Collins V, Sheffield LJ, Chiu E. et al. Problems assessing uptake of Huntington disease presymptomatic testing and a proposed solution. Eur $\mathbf{J}$ Hum Genet. 2009;17:66-70.

3. MacLeod R, Tibben A, Frontali M, Evers-Kiebooms G, Jones A, Martinez-Descales A. et al. Recommendations for the presymptomatic genetic test in Huntington's disease. Clin Genet. 2013;83:221-31.

4. Almqvist EW, Bloch M, Brinkman R, Craufurd D, Hayden MR. A worldwide assessment of the frequency of suicide, suicide attempts, or psychiatric hospitalization after presymptomatic testing for Huntington disease. Am J Hum Genet. 1999;64:1293-304.

5. Stark Z, Wallace J, Gillam L, Burgess M, Delatycki MB. Presymptomatic genetic testing for neurodegenerative conditions: how should conflicting interests within families be managed? J Med Ethics. 2016;42:640-2. 